Supporting Information for:

\title{
Electrospun Nanofibers as Substrates for Surface-Assisted Laser \\ Desorption/Ionization and Matrix-Enhanced Surface-Assisted Laser \\ Desorption/Ionization Mass Spectrometry
}

\author{
Tian Lu, Susan V. Olesik \\ Department of Chemistry and Biochemistry, The Ohio State University, \\ 100 West 18th Avenue, Columbus, Ohio 43210, United States \\ ${ }^{*}$ Corresponding author.
}

Phone: 614-292-0733. Fax: 614-688-5402. E-mail: olesik.1@osu.edu.

\section{Experiment}

Materials.

SU-8 2100, an epoxide-based negative photoresist, was purchased from MicroChem Corporation (Newton, MA). PVA (99\%+ hydrolyzed, $M_{\mathrm{w}} 89$ 000-98 000), PAN ( $M_{\mathrm{w}} 150$ 000) and $\mathrm{NaHCO}_{3}$ were purchased from Sigma-Aldrich (St. Louis, MO). SU-8 was diluted to 75 (v/v) \% with cyclopentanone (Sigma Aldrich, St. Louis, MO). PVA was dissolved in deionized water (8\%, w/w). Glutaraldehyde (GA, 25\% in water, Baker) and $\mathrm{HCl}$ (0.1 M) were added to the aqueous PVA solution prior to electrospinning as a crosslinker and catalyst, respectively. ${ }^{1}$ PAN was dissolved in $\mathrm{N}, \mathrm{N}$-dimethylformamide (DMF, Sigma Aldrich, St. Louis, MO) with a concentration of 10\% (wt\%). Angiotensin I, D-(+)-glucose, L-arginine monohydrochloride, crystal violet, polystyrene 4000 (PS 4000, standard, $M_{\mathrm{w}}$ 4130), polystyrene 2000 (PS 2000, standard, $M_{\mathrm{w}}$ 2360), poly(ethylene glycol) (PEG 3400, $M_{\mathrm{n}}$ 3400), poly(ethylene glycol) (PEG 900 000, $M_{\mathrm{w}} 900$ 000), 
CHCA, 2,5-dihydroxybenzoic acid (DHB), trifluoroacetic acid (TFA), silver trifluoroacetate, and sodium trifluoroacetate were purchased from Sigma-Aldrich (St. Louis, MO). Dithranol (DR) was purchased from Fisher Scientific (Hanover Park, IL). Methanol and tetrahydrofuran (THF) were purchased from Mallinckrodt Chemicals (Phillipsburg, NJ).

\section{Electrospinning.}

PAN (10\% and $12.5 \%$, wt $\%)$ was electrospun using previously optimized conditions of $20 \mathrm{kV}$, a distance between the tip and the collector of $20 \mathrm{~cm}$, and a flow rate of $1.5 \mathrm{~mL} / \mathrm{h}$ with relative humidity less than $50 \% .^{2}$ Porous PAN was prepared following a reported procedure. ${ }^{3}$ Briefly, $5 \%$ or $10 \%$ of $\mathrm{NaHCO}_{3}$ (wt\%) was mixed and homogeneously dispersed in 10\% PAN solution. The electrospinning condition was the same as the one used for pure PAN. After electrospinning the fiber mat was peeled off from the collector and immersed into $10 \% \mathrm{HCl}$ solution to remove $\mathrm{NaHCO}_{3}$ and create pores. Then the mat was washed with nano pure water thoroughly to remove the salt and $\mathrm{HCl}$. When the mat was still wet it was spread onto the target plate. The fiber mat adhered to the plate when it was dry. The in-situ crosslinked PVA was electrospun after adding glutaraldehyde (GA:PVA, 90:1, mol/mol) and $\mathrm{HCl}$ (HCl:GA, 1:5, mol/mol). PVA was also electrospun using previously optimized conditions of $20 \mathrm{kV}$, a distance between the tip and the collector of $20 \mathrm{~cm}$, a flow rate of $0.5 \mathrm{~mL} / \mathrm{h}$, and relative humidity of less than $30 \% .{ }^{1}$ The SU-8 was electrospun in a dark room due to its UV sensitivity. The previously optimized conditions consisted of a voltage of $9 \mathrm{kV}$, a distance between the tip and the collector of $10 \mathrm{~cm}$, and a flow rate of $1.2 \mathrm{~mL} / \mathrm{h} .{ }^{4}$ The obtained SU-8 mat was crosslinked under UV light (Sunray 400SM UV flood light, Uvitron International West Springfield, MA) for 
about 5 min. ${ }^{5}$ For all polymers, the electrospinning time varied from 5 min to 25 min to obtain a homogeneous coverage of the target plate (dimension app. $53 \times 41 \mathrm{~mm}$ ) and fibrous mats of $2 \mathrm{mg} \pm 0.5 \mathrm{mg}$. For PAN and SU-8, electrospinning about 5 min yielded 2 mg mats, while for crosslinked PVA about 20 min electrospinning time was needed. Because of the mass loss during the pyrolysis, electrospinning times of 15, 25 and $35 \mathrm{~min}$ were used to produce $2 \mathrm{mg}$ nanofibrous mats for the carbon nanofibers processed to 600 , 800 and $900{ }^{\circ} \mathrm{C}$, respectively.

\section{Fabrication of Carbon Substrates.}

The carbon nanofibrous substrates were made by pyrolysis of the crosslinked SU-8 precursor. The target plate with electrospun and crosslinked SU-8 was placed in a tube furnace (Lindberg/Blue M Asheville NC, Model: STF55346C-1) and heated under forming gas $\left(5 \% \mathrm{H}_{2}\right.$ in $\left.\mathrm{N}_{2}\right)$ at a ramp rate of $1{ }^{\circ} \mathrm{C} / \mathrm{min}$ for final temperatures of $800{ }^{\circ} \mathrm{C}$ and $900{ }^{\circ} \mathrm{C}$ and $2{ }^{\circ} \mathrm{C} / \mathrm{min}$ for $600{ }^{\circ} \mathrm{C}$. The final pyrolysis temperature was held for $6 \mathrm{~h}$ and cooled to room temperature. ${ }^{5}$

\section{Sample Preparation.}

Polystyrene with silver trifluoroacetate $(1: 1, \mathrm{w} / \mathrm{w})$ and dithranol were dissolved in THF. Poly(ethylene glycol) with sodium trifluoroacetate (1:1, w/w) and DHB were dissolved in methanol. For dynamic range study PS 4000 solution $(250 \mathrm{mg} / \mathrm{mL}$ in THF with 250 $\mathrm{mg} / \mathrm{mL}$ silver trifluoroacetate) and PS 4000/PS 2000 blend (250 mg/mL in THF with 250 $\mathrm{mg} / \mathrm{mL}$ silver trifluoroacetate and 5\% PS 2000, mol\%) were prepared. Glucose and arginine were dissolved in water $(1 \mathrm{mg} / \mathrm{mL})$. Crystal violet was dissolved in methanol (5 $\mathrm{mg} / \mathrm{mL})$. Angiotensin I and matrix CHCA were dissolved in acetonitrile/water (1:1, v/v) with $0.1 \%$ trifluoroacetic acid. Dried droplet by the multiple-layer spotting method was 
used for sample preparation. ${ }^{6} 0.1 \mu \mathrm{L}$ of the analyte solution was applied on the target plate for SALDI analysis. Matrix solution was applied over the dried analyte. Due to the limit of the solubility of CHCA and dithranol, multiple layers of the solution were applied to reach different matrix/analyte ratios (Table S-1). The electrospun substrates were removed from the target plate after use, and the target plate was reused after thoroughly cleaning the surface with THF, acetone, methanol, and water followed by sonication in methanol for $15 \mathrm{~min}$.

\section{Instrumentation.}

The mass spectra were collected using a Microflex MALDI-TOF Bruker mass spectrometer in positive ion mode. A nitrogen laser at $337 \mathrm{~nm}$ with a pulse width of $3 \mathrm{~ns}$ was used. The ion acceleration potential was $20 \mathrm{kV}$. The laser power used to obtain the spectra and to optimize the S/N ratios was slightly above the ionization threshold. For PEG 900000 linear mode was used. For all the other samples reflector mode was used. Each spectrum was the summation of 120 shots, unless otherwise noted. All of the results were repeated at least three times. FlexAnalysis ${ }^{\mathrm{TM}}$ software was used for data analysis. For angiotensin I, SNAP was used for the peak pick and S/N determination due to its isotopic pattern, and for all the other analytes CENTROID was used. ${ }^{7}$

A Hitachi S-300 (Hitachi High Technologies, America, Inc., Pleasanton, CA) scanning electron microscope (SEM) was used to obtain images of the nanofibrous substrates. A stainless steel plate of the same dimension as the target plate was used as the collector during electrospinning for the samples used in SEM imaging. 
Table S-1. Average diameters of the electrospun nanofibers.

\begin{tabular}{c|c} 
& Diameter $(\mathrm{nm})$ \\
\hline Carbon $\left(600{ }^{\circ} \mathrm{C}\right)$ & $195 \pm 80$ \\
Carbon $\left(800{ }^{\circ} \mathrm{C}\right)$ & $150 \pm 55$ \\
Carbon $\left(900{ }^{\circ} \mathrm{C}\right)$ & $140 \pm 50$ \\
PAN $(10 \%)$ & $460 \pm 90$ \\
PAN $(12.5 \%)$ & $880 \pm 90$ \\
PAN $\left(10 \%\right.$ with $\left.5 \% \mathrm{NaHCO}_{3}\right)$ & $470 \pm 100$ \\
PAN $\left(10 \%\right.$ with $\left.10 \% \mathrm{NaHCO}_{3}\right)$ & $430 \pm 80$ \\
PVA & $190 \pm 50$ \\
SU-8 & $420 \pm 90$
\end{tabular}


Table S-2. S/N of ME-SALDI-TOF spectra with different substrates.

\begin{tabular}{|c|c|c|c|c|}
\hline Analyte (mg/mL) & Matrix (mg/mL) & Carbon $\left(600^{\circ} \mathrm{C}\right)$ & Carbon $\left(800^{\circ} \mathrm{C}\right)$ & Stainless steel \\
\hline PEG 3400 (5) & DHB (40) & $48 \pm 7$ & $15 \pm 10$ & $80 \pm 10$ \\
\hline PEG 3400 (5) & DHB (80) & $52 \pm 5$ & $55 \pm 8$ & $78 \pm 8$ \\
\hline PEG 3400 (5) & DHB (160) & $50 \pm 3$ & $110 \pm 20$ & $130 \pm 10$ \\
\hline PEG 3400 (10) & DHB (40) & $36 \pm 6$ & $50 \pm 9$ & $70 \pm 15$ \\
\hline PEG 3400 (10) & DHB (80) & $61 \pm 7$ & $80 \pm 20$ & $100 \pm 20$ \\
\hline PEG 3400 (10) & DHB (160) & $77 \pm 8$ & $90 \pm 20$ & $130 \pm 10$ \\
\hline PEG 3400 (20) & DHB (40) & $40 \pm 9$ & $60 \pm 9$ & $70 \pm 20$ \\
\hline PEG 3400 (20) & DHB (80) & $39 \pm 4$ & $100 \pm 12$ & $100 \pm 10$ \\
\hline PEG 3400 (20) & DHB (160) & $57 \pm 6$ & $100 \pm 20$ & $100 \pm 9$ \\
\hline PS 4000 (25) & DR $(40 \times 1)$ & $90 \pm 20$ & $13 \pm 6$ & $67 \pm 9$ \\
\hline PS 4000 (25) & DR $(40 \times 3)$ & $80 \pm 20$ & $18 \pm 4$ & $90 \pm 10$ \\
\hline PS 4000 (25) & DR $(40 \times 5)$ & $95 \pm 15$ & $40 \pm 10$ & $95 \pm 10$ \\
\hline PS 4000 (50) & DR $(40 \times 1)$ & $90 \pm 10$ & $20 \pm 7$ & $62 \pm 9$ \\
\hline PS 4000 (50) & DR $(40 \times 3)$ & $130 \pm 20$ & $150 \pm 20$ & $120 \pm 20$ \\
\hline PS 4000 (50) & DR $(40 \times 5)$ & $105 \pm 20$ & $50 \pm 10$ & $90 \pm 20$ \\
\hline PS 4000 (100) & DR $(40 \times 1)$ & $70 \pm 15$ & $70 \pm 20$ & $45 \pm 9$ \\
\hline PS 4000 (100) & DR $(40 \times 3)$ & $80 \pm 20$ & $80 \pm 7$ & $60 \pm 15$ \\
\hline PS 4000 (100) & DR $(40 \times 5)$ & $190 \pm 20$ & $160 \pm 17$ & $125 \pm 7$ \\
\hline Angiotensin I (0.5) & CHCA (10) & $1500 \pm 300$ & $4300 \pm 400$ & $1500 \pm 100$ \\
\hline Angiotensin I (1) & CHCA (5) & $1200 \pm 200$ & $4000 \pm 1000$ & $1800 \pm 300$ \\
\hline Angiotensin I (1) & CHCA (10) & $3400 \pm 200$ & $4700 \pm 800$ & $2000 \pm 150$ \\
\hline Angiotensin I (1) & CHCA $(10 \times 2)$ & $3300 \pm 400$ & $2100 \pm 200$ & $2400 \pm 300$ \\
\hline Angiotensin I (2) & CHCA (5) & $1600 \pm 500$ & $1200 \pm 500$ & $1700 \pm 300$ \\
\hline Angiotensin I (2) & CHCA (10) & $4400 \pm 200$ & $2400 \pm 300$ & $2000 \pm 200$ \\
\hline Angiotensin I (2) & CHCA $(10 \times 2)$ & $3400 \pm 350$ & $5400 \pm 650$ & $1300 \pm 300$ \\
\hline
\end{tabular}

The applied volume of sample and matrix solution was $0.1 \mu \mathrm{L}$. 20 shots were used to acquire each spectrum. "Sweet spot" were searched all over the sample spot to obtain the optimum signal S/N rations. Five replicates were performed for each sample. Since the standard deviation listed in Table S-1 was calculated from five spectra obtained only from "sweet spots" by searching all over the sample, the standard deviation cannot be used to represent the shot-to-shot reproducibility like that discussed in the SALDI section. 

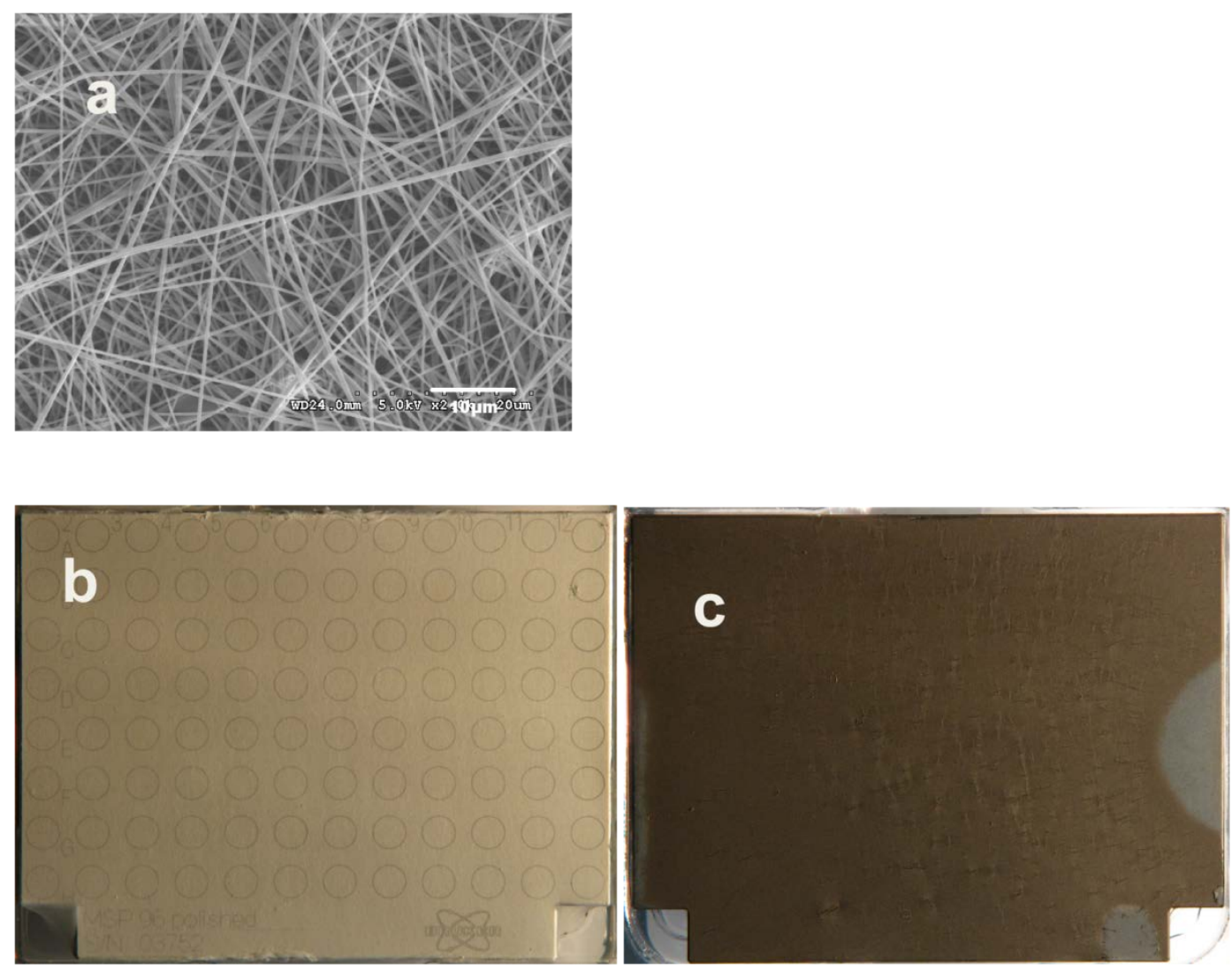

Figure S-1. SEM image of the electrospun (a) PAN (10\%) substrate, and digital photographs of target plates with (b) PAN and (c) carbon nanofibers processed to $600{ }^{\circ} \mathrm{C}$ as substrates,

All the other carbon and polymeric substrates have similar nanofibrous structures. PVA and SU-8 also showed the circles on the stainless steel target plate after electrospinning. Due to the high temperature treatment those circles disappeared after pyrolysis of the carbon substrates. 


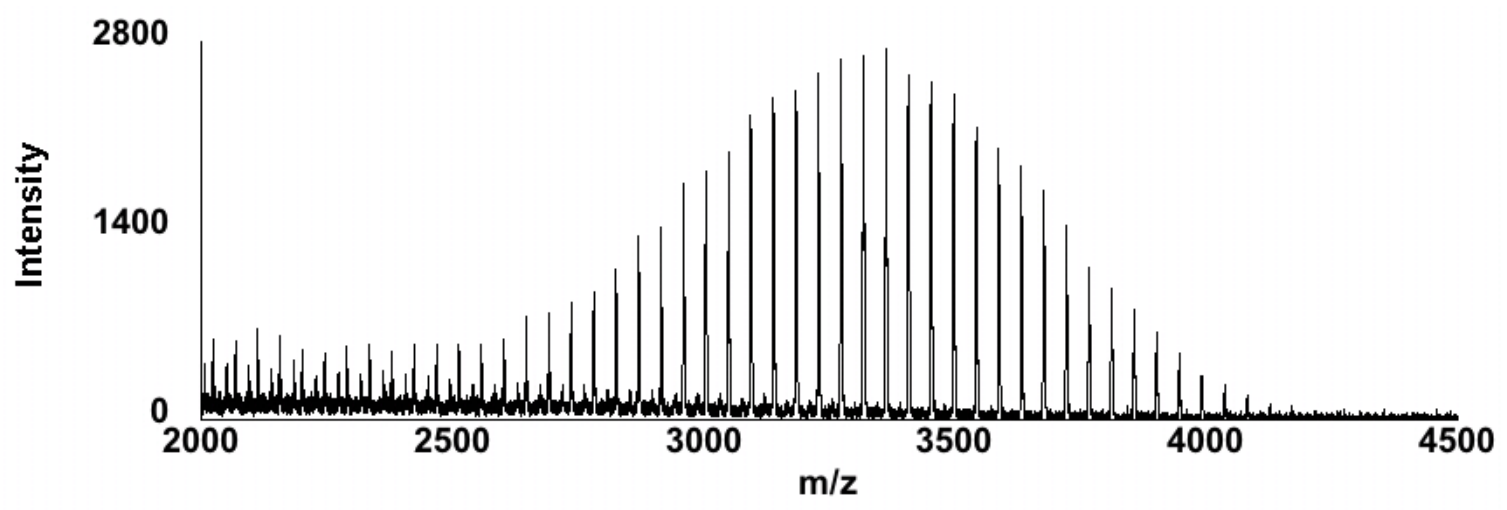

Figure S-2. SALDI mass spectrum of PEG $3400(20 \mathrm{mg} / \mathrm{mL})$ using carbon processed to $800{ }^{\circ} \mathrm{C}$ substrate. Laser intensity $30 \mu \mathrm{j}$. 


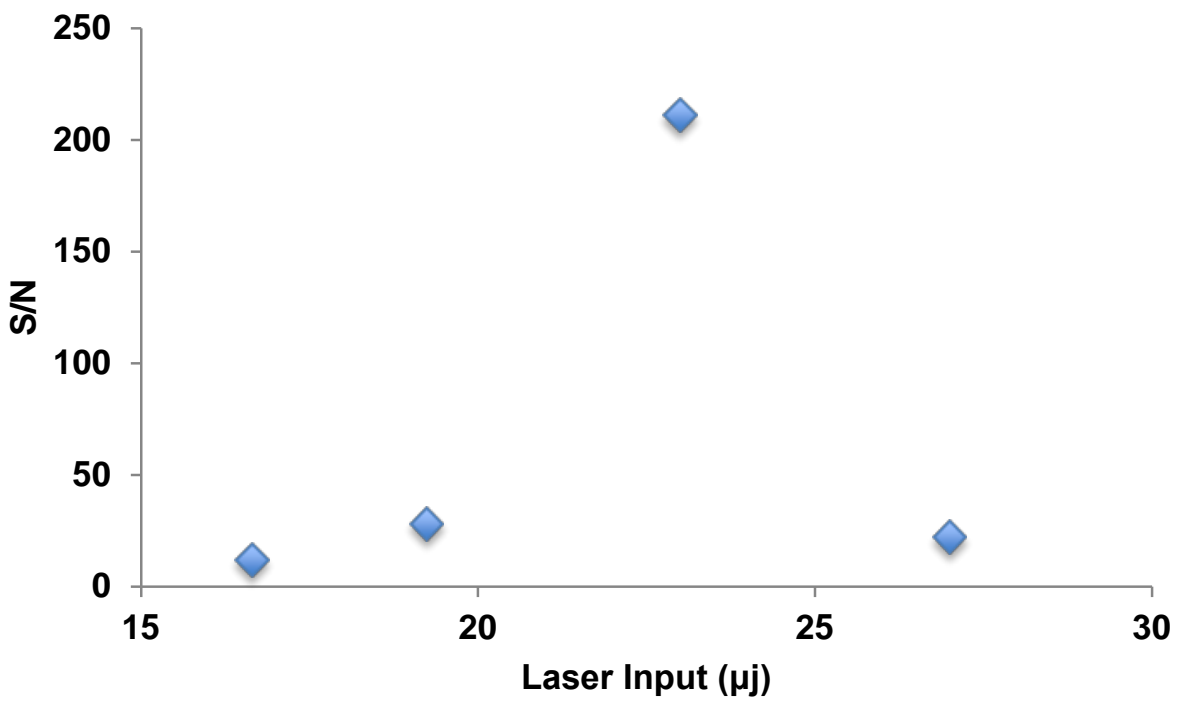

Figure S-3. Optimization of laser energy of PEG $3400(20 \mathrm{mg} / \mathrm{mL})$ with carbon substrate processed to $800^{\circ} \mathrm{C}$. 

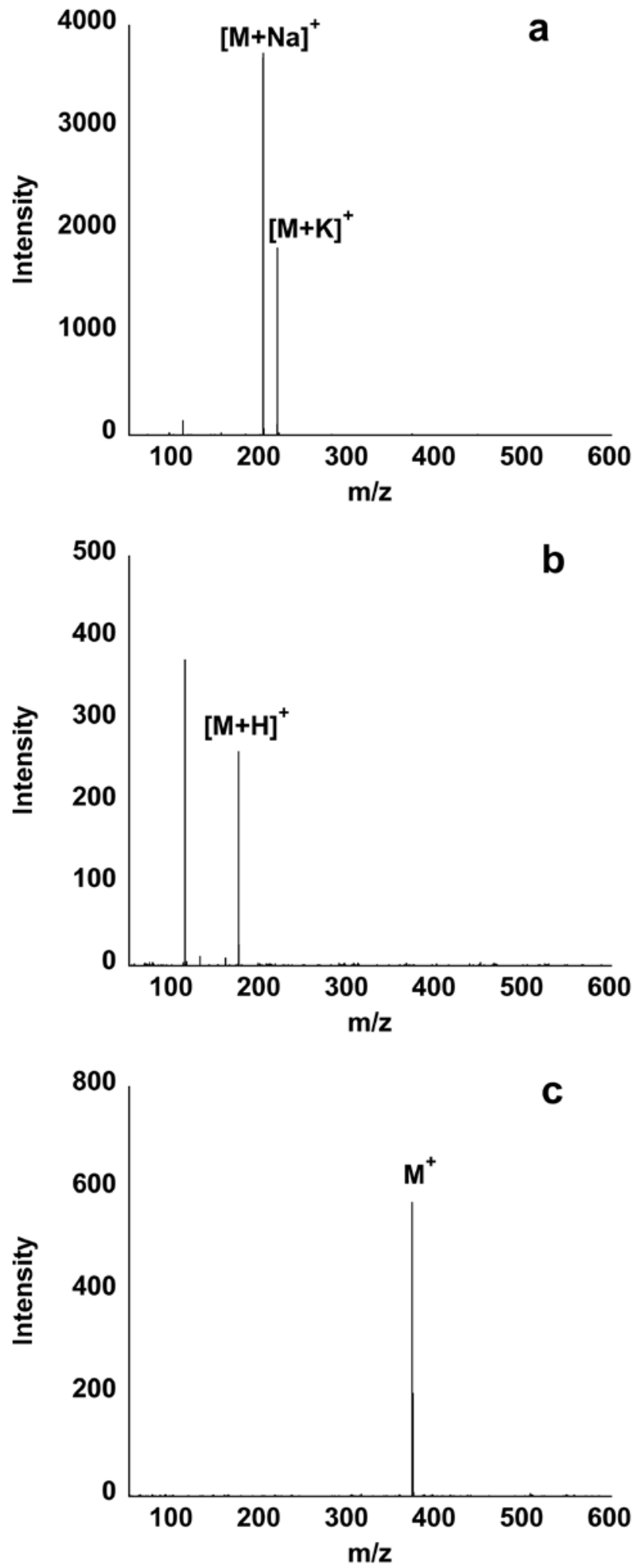

Figure S-4. SALDI-TOF mass spectra of (a) glucose $(1 \mathrm{mg} / \mathrm{mL})$, (b) arginine $(1 \mathrm{mg} / \mathrm{mL})$ and (c) crystal violet (5 mg/mL) using the carbon substrate processed to $800{ }^{\circ} \mathrm{C}$. The peak at m/z of 114 in (b) is from impurity. 


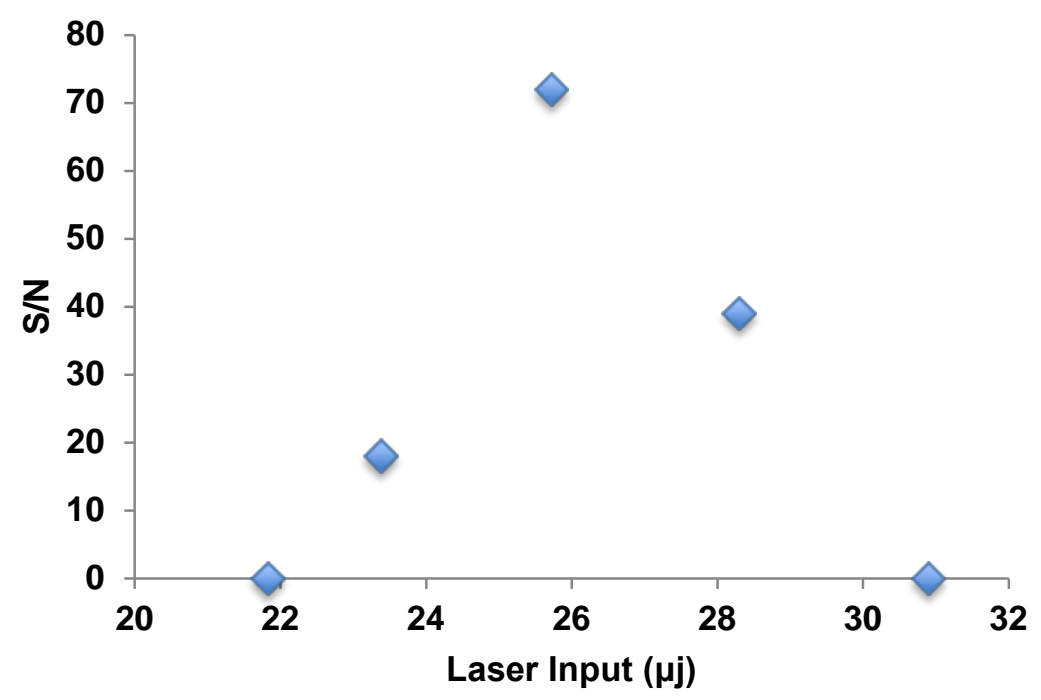

Figure S-5. Optimization of laser energy of PS $4000(50 \mathrm{mg} / \mathrm{mL})$ with PAN (10\%) substrate. 


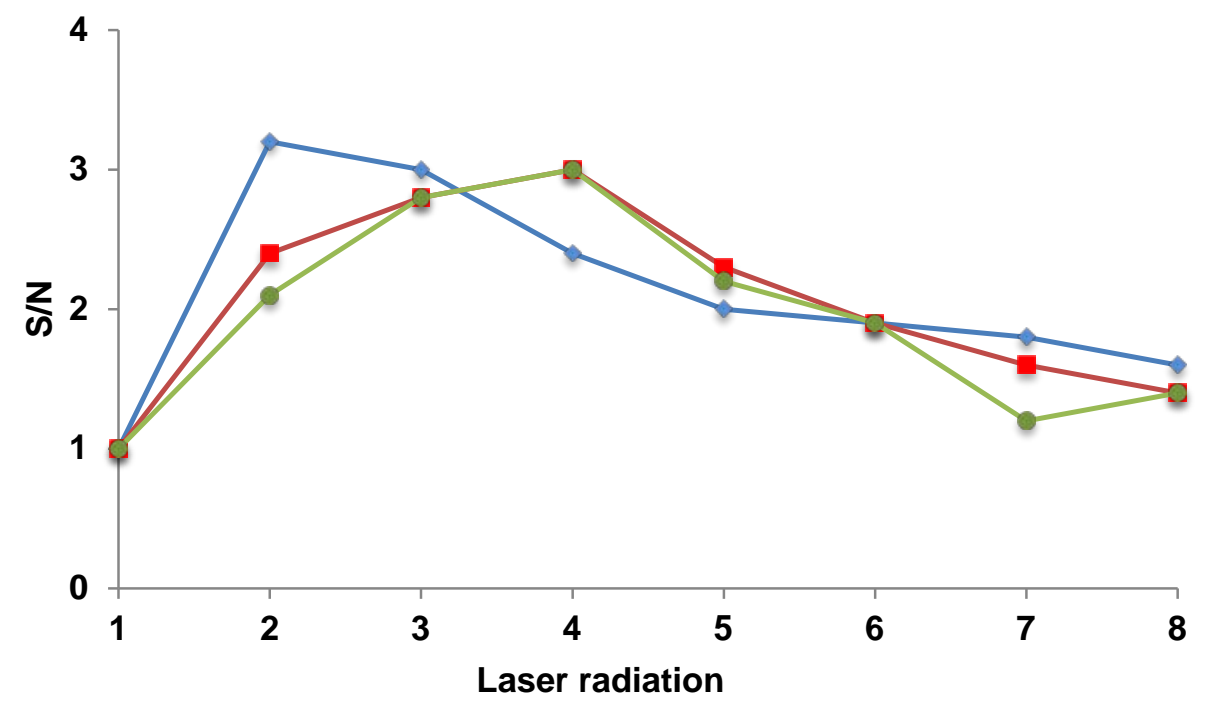

Figure S-6. S/N dependence with number of laser radiations on the same spot of the PS 4000 using PVA substrate. Each laser radiation contains 20 shots. (○) $100 \mathrm{mg} / \mathrm{mL}$, (匹) $50 \mathrm{mg} / \mathrm{mL},(\diamond) 25 \mathrm{mg} / \mathrm{mL}$. 

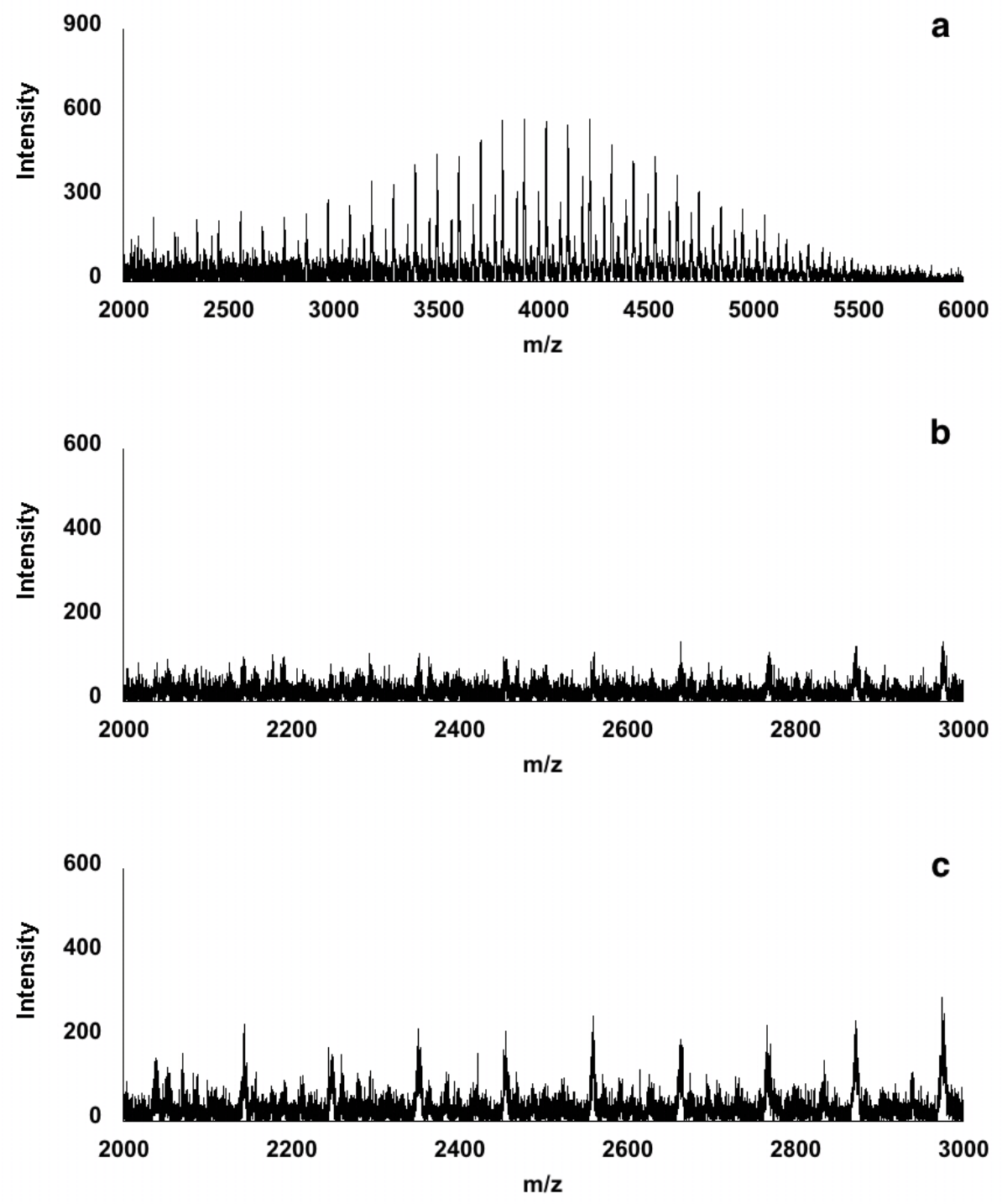

Figure S-7. SALDI-TOF mass spectra of (a) 5\% PS 2000 mixed with PS 4000 (mol \%) and the expanded low mass region of (b) PS 4000 and (c) 5\% PS 2000 mixed with PS 4000 (mol \%) using the PAN substrate. 


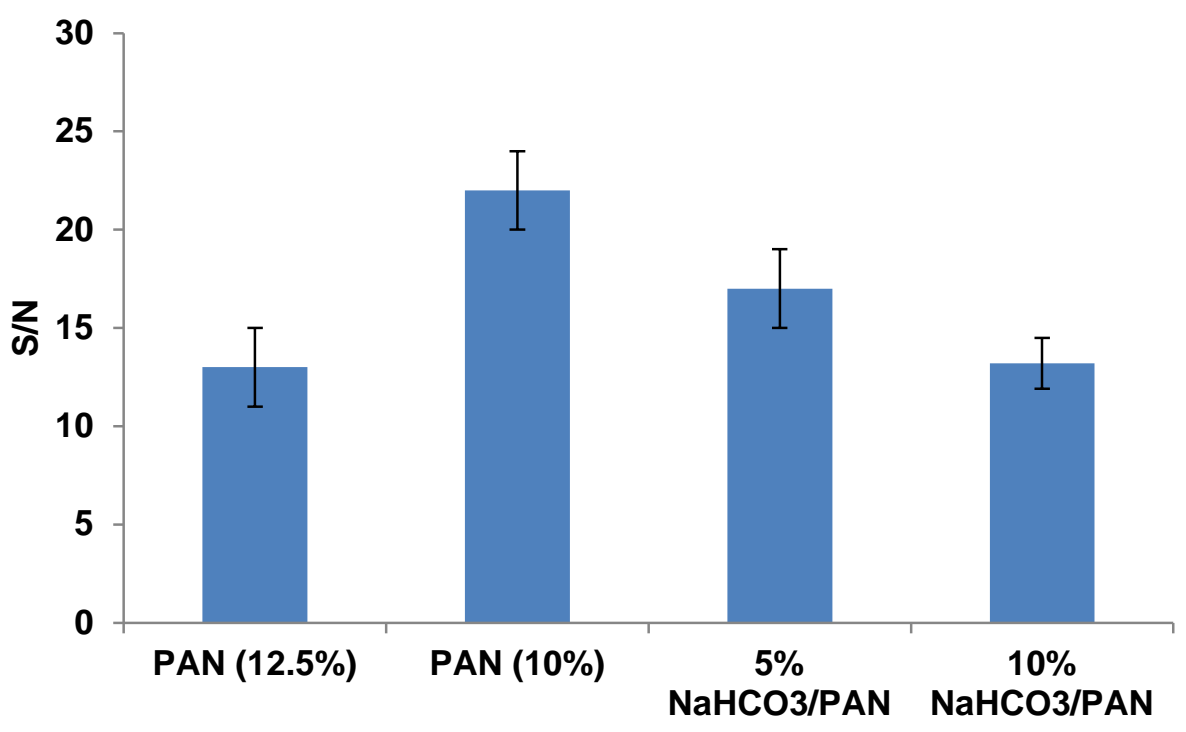

Figure S-8. S/N of PS $4000(50 \mathrm{mg} / \mathrm{mL})$ on PAN substrates with different diameters, pore sizes and pore density. 


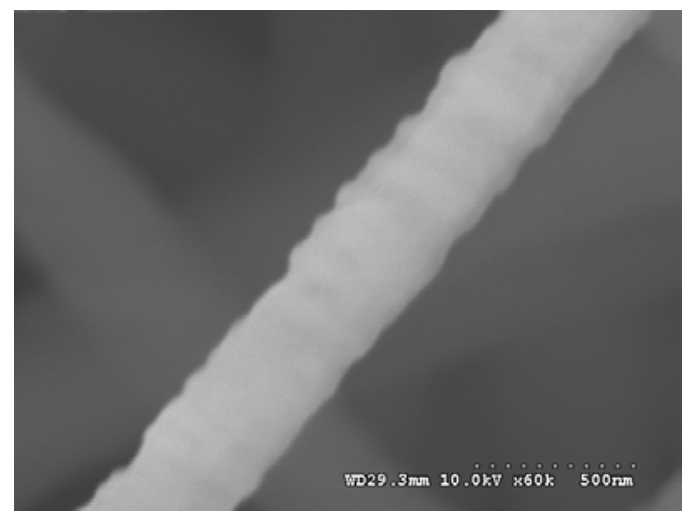

Figure S-9. SEM image of porous PAN prepared by adding $10 \% \mathrm{NaHCO}_{3}$. 

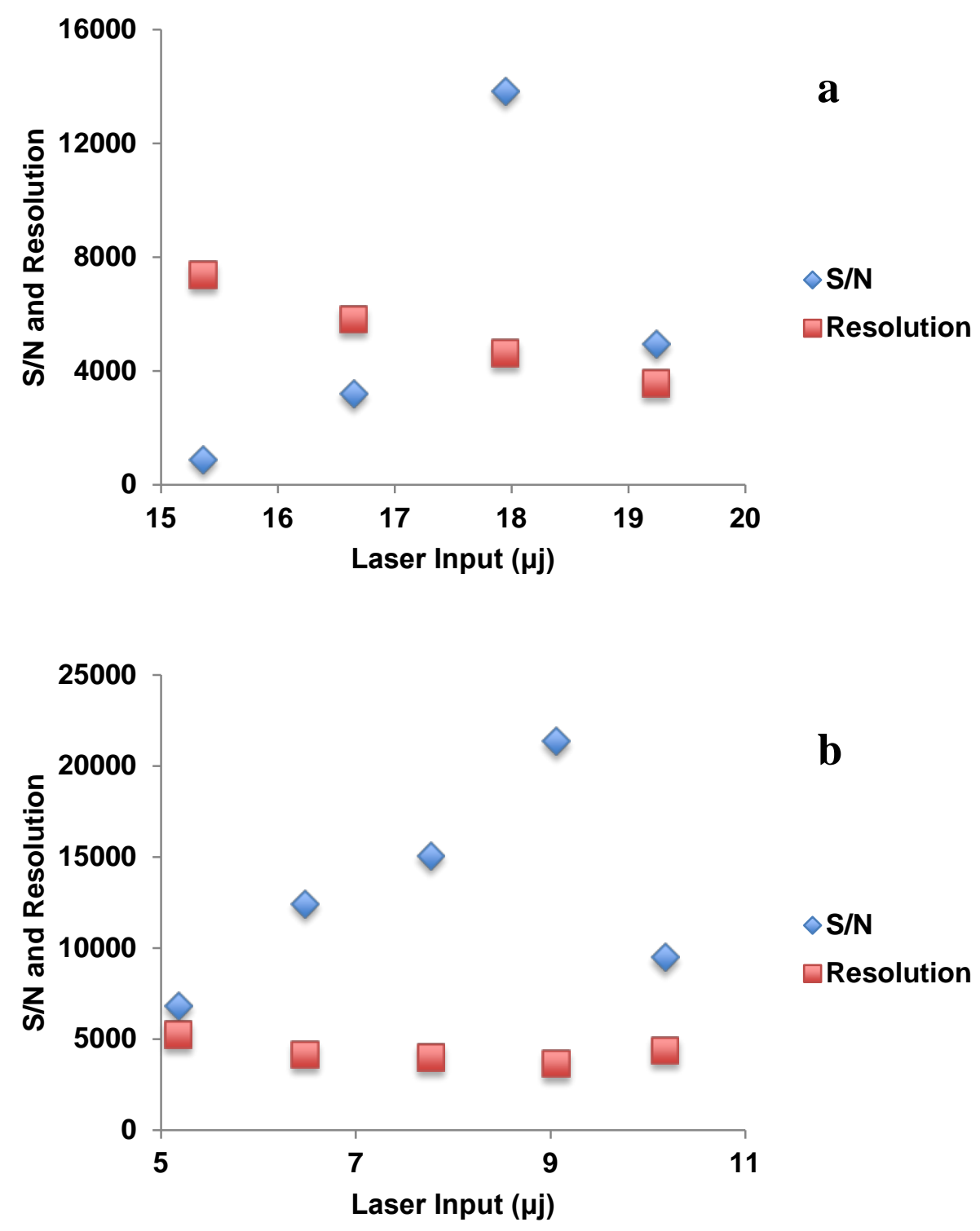

Figure S-10. Optimization of S/N of angiotensin I ( $2 \mathrm{mg} / \mathrm{mL})$ using CHCA $(2 \times 10$ $\mathrm{mg} / \mathrm{mL}$ ) as matrix with (a) carbon substrate processed to $800{ }^{\circ} \mathrm{C}$ and (b) PVA substrate. 
a

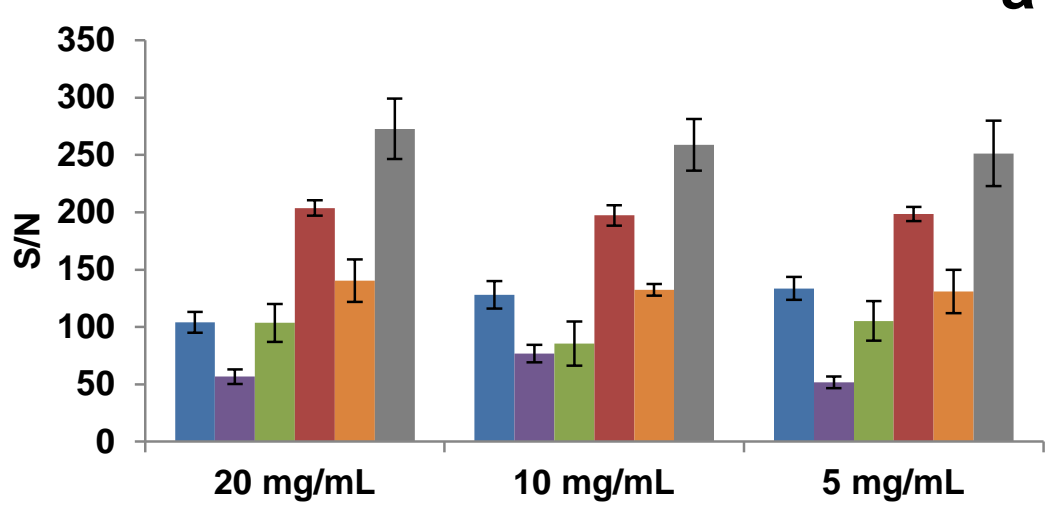

b
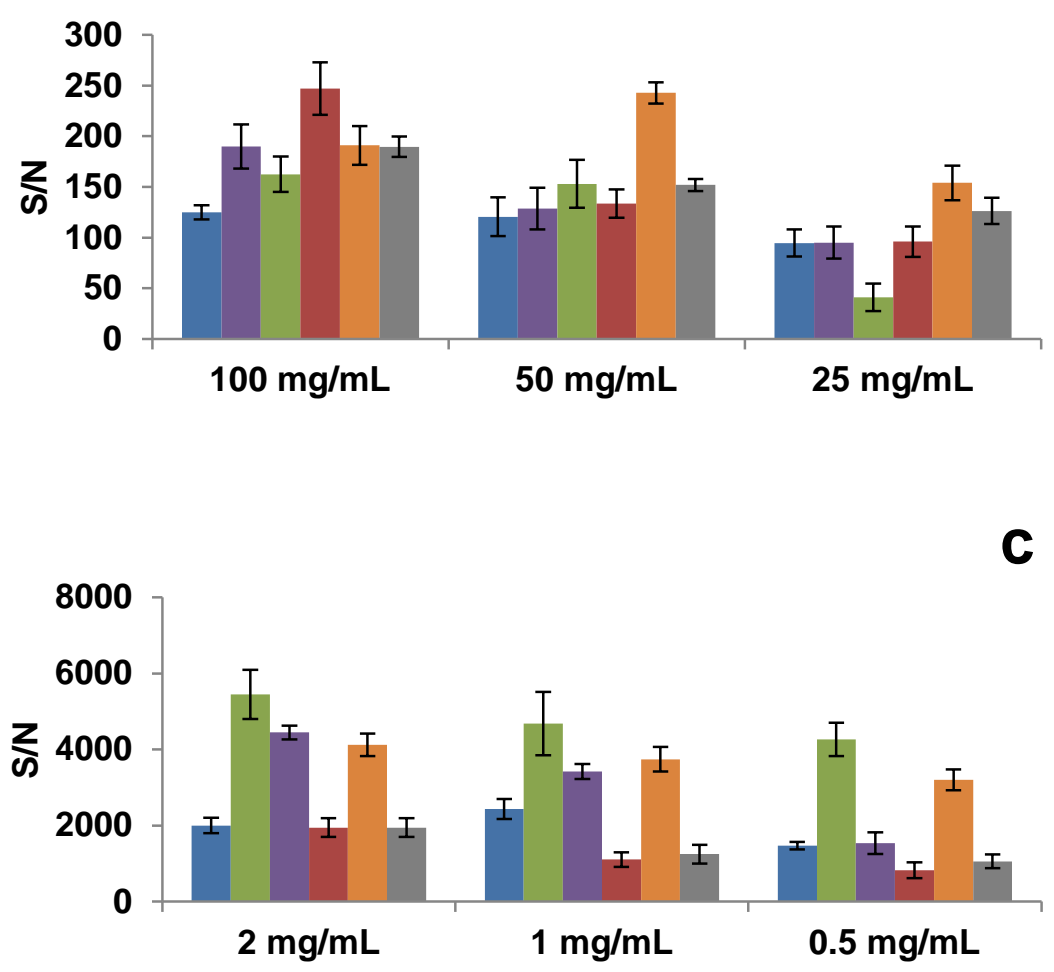

Figure S-11. S/N ratios of (a) PEG 3400, (b) PS 4000, and (c) angiotensin I on different substrates:( $\square)$ stainless steel, ( $\square)$ carbon processed to $800{ }^{\circ} \mathrm{C},(\square)$ carbon processed to $600{ }^{\circ} \mathrm{C}$, (口) PAN, ( $\square$ ) PVA, ( $\square$ ) SU-8. S/N ratios calculated from five spectra with 20 shots each. The error bars show the standard deviations. 

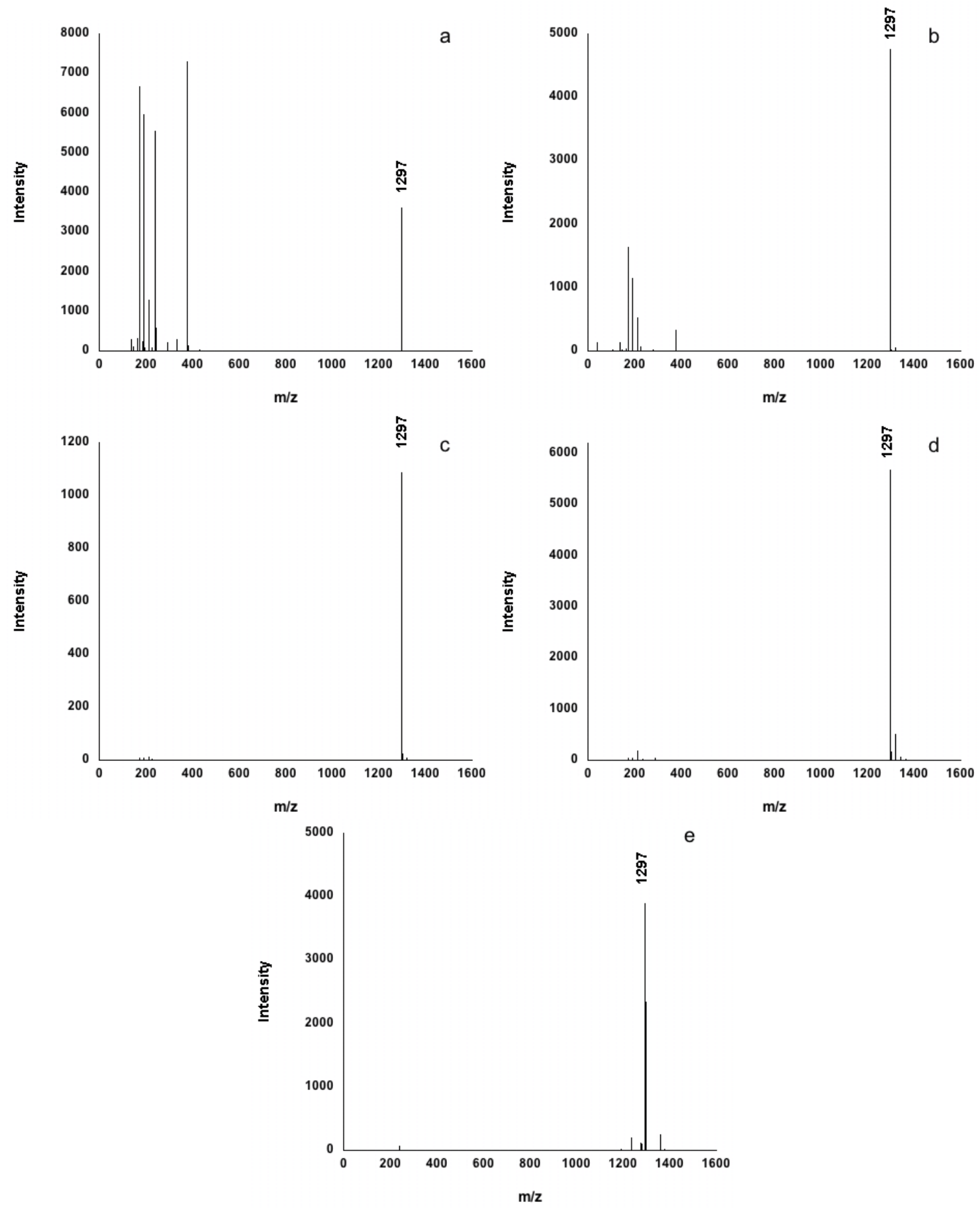

Figure S-12. ME-SALDI spectra of angiotensin I using carbon substrate processed to $800{ }^{\circ} \mathrm{C}$ with concentrations of $2 \mathrm{mg} / \mathrm{mL}$ (a), $1 \mathrm{mg} / \mathrm{mL}$ (b), $0.5 \mathrm{mg} / \mathrm{mL}$ (c), stainless steel substrate with concentration of $0.5 \mathrm{mg} / \mathrm{mL}$ (d), and PVA substrate with concentration of $1 \mathrm{mg} / \mathrm{mL}$ (e). The matrix/analyte ratios were kept the same for all samples (1:10, w/w). 


\section{References}

${ }^{1}$ Lu, T.; Olesik, S. V. J. Chromatogr., B: Anal. Technol. Biomed. Life Sci. 2013, 912, 98104.

${ }^{2}$ Clark, J. E.; Olesik, S. V. Anal. Chem. 2009, 81, 4121-4129.

${ }^{3}$ Ma, G.; Yang, D.; Nie, J. Polym. Adv. Technol. 2009, 20, 147-150.

${ }^{4}$ Steach, J. K.; Clark, J. E.; Olesik, S. V. J. Appl. Polym. Sci. 2010, 118, 405-412.

${ }^{5}$ Clark, J. E.; Olesik, S. V. J. Chromatogr., A 2010, 1217, 4655-4662.

${ }^{6}$ Meier, M. A. R.; Schubert, U. S. Rapid Commun. Mass Spectrom. 2003, 17, 713-716.

${ }^{7}$ Kempka, M.; Sjodahl, J.; Bjork, A.; Roeraade, J. Rapid Commun. Mass Spectrom. 2004, 18, 1208-1212. 